\title{
Um além que vem do passado: o evolucionismo e o caráter regressivo e patogênico das pulsões
}

\author{
The "beyond" that comes from the past: evolutionism and the regressive and \\ pathological character of drive
}

\section{Vinícius Armiliato* \\ Francisco Verardi Bocca*}

Resumo: Este artigo traz uma reflexão sobre a influência que a Biologia evolutiva exerceu sobre Sigmund Freud no tocante à teoria das pulsões e à noção de patologia que a acompanha. Também, notadamente quanto às suas tendências regressivas, conforme apresentado em Além do princípio do prazer, publicação pródiga de referenciais evolucionários, especialmente da compreensão filogenética da espécie humana, ou seja, da teoria da recapitulação de Ernst Haeckel, articulada aos fenômenos clínicos e culturais. Amparados em Georges Canguilhem, observamos que a mesma Biologia cumpre função normativa na qualificação das manifestações humanas. Assim, mostraremos que o recurso a ela serviu de apoio para Freud estabelecer uma concepção psicanalítica de sujeito igualmente normativa, a saber, dotado de um psiquismo regressivo e com uma natureza de caráter patogênico, cuja tendência biológica o faz repetir comportamentos do passado. Se trata de uma opção teórica em detrimento da ruptura e da variação como norteadora de sua história, assim como da história da espécie humana.

Palavras-chave: Psicanálise; Ernst Haeckel; Sigmund Freud; Georges Canguilhem; Biologia evolutiva; Patologia

Abstract: This article reflects on the influence that evolutionary biology had on Sigmund Freud regarding the theory of drives and the notion of pathology that accompanies it. Also, notably regarding its regressive tendencies, as presented in Beyond the Pleasure Principle, a publication with outstanding evolutionary references, especially on the phylogenetic understanding of the human species, that is, the recapitulation theory of Ernst Haeckel, a theory linked to clinical and cultural phenomena. Supported by Georges Canguilhem, we observe that the same Biology fulfills a normative function in the qualification of human manifestations. Thus, we show that the resource to it served as support for Freud to establish a psychoanalytic conception of subject likewise normative, that is, endowed with a regressive and pathological psyche in its nature, whose biological tendency makes it repeat past behaviors. This approach represents a theoretical option to the detriment of rupture and variation as a guide of its history, as well as the history of the human species. Keywords: Psychoanalysis; Ernst Haeckel; Sigmund Freud; Georges Canguilhem; Evolutionary biology; Pathology

Pós-doutorado em Filosofia na Pontifícia Universidade Católica do Paraná, Curitiba, PR. E-mail: vinicius.arm@gmail.com ORCID: https://orcid.org/0000-0003-2288-3820

** Professor de Filosofia na Pontifícia Universidade Católica do Paraná, Curitiba, PR. E-mail: francisco.bocca@pucpr.br ORCID: https://orcid.org/0000-0001-6337-9263 
Quando levamos em conta as leituras que Freud realizou da Biologia evolutiva reavaliamos o estranhamento que as proposições especulativas presentes em Além do princípio do prazer causaram entre muitos de seus leitores e comentadores. Especialmente os argumentos de que nela teria ocorrido uma mudança de direção no interior da obra freudiana. Há também os que procuram relativizar a influência da Biologia.

Conforme Simanke, a abordagem das incursões biológicas de Freud pela recepção da psicanálise:

[...] pareceu frequentemente exigir uma desconsideração do contexto naturalista em que elas foram originalmente elaboradas, rebaixado a uma idiossincrasia ou excentricidade pessoal de Freud, um apelo sentimental ao ideal epistêmico adquirido na juventude, tornado anacrônico pelo próprio caráter revolucionário e "subversivo" da teoria ${ }^{1}$.

O próprio Freud contribuiu ao admitir que se tratava de um ensaio especulativo. Em sua Autobiografia ${ }^{2}$ declarou que em Além do princípio do prazer, teria dado livre curso à sua tendência especulativa, contida durante muito tempo. No entanto, é preciso lembrar que mesmo o especular no campo da ciência exige uma elaboração investigativa amplamente sustentada em evidências empíricas. No caso de Além do princípio do prazer, encontrou-as na Biologia evolutiva desde seu ingresso na Faculdade de Medicina de Viena, na década de 1870.

A abordagem histórica da espécie humana em dimensões escalares possibilitou a hipótese do retorno a estágios primevos do psiquismo, seja nas manifestações patológicas, seja nas oníricas, ou ainda, nas culturais. Deste modo, o próprio percurso regressivo da pulsão seguiria a trajetória evolutiva da espécie. Note-se que se trata de uma tese frequente e razoável no meio científico frequentado por Freud.

Tal influência será apresentada, inicialmente, mostrando os elementos presentes no debate evolucionista frequentado por Freud, e que foram por ele incorporados, notadamente a ideia de tempo evolutivo (ontogenético e filogenético), além da regressão. Para o que, ainda que não única, a teoria da recapitulação de Ernst Haeckel ocupou um lugar de destaque. Em seguida, mostraremos o modo como esses elementos foram utilizados por Freud em distintos pontos de sua obra, especialmente em Além do princípio do prazer. Ao final, apresentamos uma reflexão a partir de Georges Canguilhem, mostrando o efeito que a Biologia evolutiva, ao ser normativa, exerceu nas ponderações de Freud sobre as pulsões e o caráter patológico destas, cujo resultado foi sua ponderação sobre um funcionamento psíquico regressivo, repetitivo e tendente à patologia pela espécie humana, em detrimento de uma perspectiva ruptiva, aberta e criativa.

\footnotetext{
${ }^{1}$ SIMANKE, A psicanálise freudiana e a dualidade entre ciências naturais e ciências humanas, 226.

${ }^{2}$ FREUD, Autobiografía, p. 2790.
} 


\section{O evolucionismo e o fator tempo}

Em suas publicações Freud fez várias menções ao evolucionismo e à figura de Charles Darwin. A mais famosa destas refere-se aos golpes narcísicos que achados científicos conferiram à humanidade, cuja sequência seria o heliocentrismo copernicano, o evolucionismo darwinista e, por fim, a psicanálise freudiana ${ }^{3}$. Segundo Assoun ${ }^{4}$, este ranqueamento era frequente entre biólogos de então como Emil Du Boys-Reymond, além do principal divulgador da obra de Darwin em língua alemã, Haeckel. A atmosfera darwiniana era presente nos círculos progressistas frequentados por Freud. Segundo Alfred Kelly, o darwinismo, nos anos 1860 e 1870, "foi uma arma contra tais bastiões do conservadorismo, tais como as igrejas e a educação pública"5.

Como Ritvo mostrou, especialmente entre os anos de 1865 e 1882, período que abrange desde os estudos de Freud no Gymnasium de Viena até suas pesquisas no laboratório de Ernst Brücke, sua vida acadêmica coincidiu com o começo da reorganização da Biologia no interior do paradigma darwiniano ${ }^{6}$, de tal modo que, para a autora, pode-se encontrar na obra de Freud "[...] fossilizada a teoria evolucionista da época de Darwin, inclusive aspectos eliminados pelo tempo"7.

\footnotetext{
${ }^{3}$ FREUD, Una dificultad del psicoanálisis, p. 2434-5; FREUD, Psicoanálisis, p. 2300. Com relação a outras referências explícitas ao evolucionismo, encontramos desde cartas a Emil Fluss em 1874 (BOEHLICH; FREUD, Lettres de jeunesse, p. 172), até trabalhos posteriores, como quando aponta as expectativas que depositara no evolucionismo (FREUD, Autobiografía, p. 2762; FREUD, Nuevas lecciones introductorias al psicoanalisis, p. 3200; FREUD, Más allá del Principio del Placer, p. 2539). Finalmente, quanto à necessidade do estudo da Biologia na formação de um psicanalista (FREUD, Análisis profano, p. 2954).

${ }^{4}$ ASSOUN, Introduction à l'épistémologie freudienne, p. 68.

${ }^{5}$ KELLY, The descent of Darwin, p. 7. "Talvez seja mais exato falar de vários darwinismos populares do que de um sistema unificado de ideias. Praticamente qualquer um poderia apelar para a autoridade do darwinismo. Materialistas, idealistas, aristocratas, democratas, conservadores, liberais e socialistas, protagonistas de praticamente qualquer tom religioso, todos estacavam suas afirmações no território darwiniano" (KELLY, The descent of Darwin, p. 7)

${ }^{6}$ Ainda enquanto estudante sob a supervisão de Carl Claus, Freud publicou seu primeiro trabalho científico o qual procurava atestar enunciados evolucionistas, Observações sobre a estrutura delicada dos órgãos lobados descritos como testículos nas enguias (FREUD, Observations de la conformation de l'organe lobé de l'anguille décrit comme grande gérminale mâle). Em publicações posteriores, sob a supervisão de Ernst Brücke encontramos Sobre a origem das raízes nervosas posteriores na medula espinhal dos Ammocoetes (Petromyzon planeri), de 1877 e Sobre os gânglios espinhais e a medula espinhal do Petromyzon, de 1878 (FREUD, Sinopses dos escritos do Dr. Sigmund Freud 1877/1897).

${ }^{7}$ RITVO, A influência de Darwin sobre Freud, p. 9. Sulloway ratifica essa consideração. A pesquisa do autor demonstrou que a presença do debate evolutivo entre os cientistas da geração de Freud "tornou-se tão extensa que o próprio Freud provavelmente nunca soube o quanto ele realmente devia a esta fonte intelectual" (SULLOWAY, Freud: biologist of the mind, p. 239). Os trabalhos de Assoun (ASSOUN, Freudisme et darwinisme, p. 1746) e de Winograd (WINOGRAD, Freud e a fábrica da alma, p. 57) também apresentam tal presença. Por fim, é preciso citar um dos primeiros trabalhos a mostrar tal influência, trazido por Bernfeld (BERNFELD, Freud's scientific beginnings, p. 73 e ss.)
} 
Nesse sentido, conforme Ritvo indicou, não se trata unicamente de uma apropriação de Darwin como figura de autoridade, mas sim, uma apropriação de Darwin e do darwinismo, do conjunto de pressupostos sobre a vida, sua origem e organização, sustentados pelos naturalistas da segunda metade do século XIX. Nesse âmbito, sua apropriação do evolucionismo foi significativamente enviesada pelas obras de Haeckel. Este se alinhou ao evolucionismo de Darwin, Lamarck, Herbert Spencer, August Weismann que, a despeito de divergências, subscreviam um ponto em comum, o de que as espécies não são fixas e assim estão sujeitas a mudanças ao longo de seu desenvolvimento histórico (filogenético).

Quanto ao aspecto histórico, Canguilhem indicou que as teorias transformistas como a de Darwin fomentaram no pensamento biológico a construção de linhas de continuidade entre as diferentes espécies. Nesse sentido, obras como A origem das espécies (1859), A descendência do homem (1871) e, por fim, A expressão das emoções no homem e nos animais (1872), sustentaram a continuidade entre a espécie humana e as demais no princípio evolutivo, como disse, "da identidade, naturalmente fundada, de duas relações: de anterioridade à posteridade e de inferioridade à superioridade"8.

Quando a noção de que o tempo histórico ganhou dimensões escalares e se tornou mais evidente através da geologia (notadamente a de Charles Lyell), provocou o enfraquecimento do argumento fixista. Em seu lugar, surgiram explicações de como as transformações ocorreram nos seres de modo a resultar em suas formas atuais ${ }^{9}$. Neste caso, A origem das espécies fortaleceu o argumento transformista segundo o qual as espécies animais não são criaturas que mantêm a mesma estrutura desde sua origem. Com efeito,

\footnotetext{
${ }^{8}$ CANGUILHEM, L'Homme et l'animal du point de vue psychologique selon Charles Darwin, p. 113.

${ }^{9}$ Nesse sentido, é emblemática a fala de Spencer: "Certamente, se uma simples célula, quando sujeita a certas influências, torna-se um homem no espaço de vinte anos, não há nada de absurdo na hipótese de que sob certas circunstâncias, uma célula pode, no curso de milhões de anos, dar origem à raça humana" (SPENCER, The Development Hypothesis, p. 6). Na sequência desta passagem, Spencer, demandando ao leitor se é mais razoável acreditar que houveram 10 milhões de criações independentes, uma para cada espécie animal e vegetal, ou que ocorreram sucessivas modificações ao longo do tempo, Spencer sugeriu que aqueles que afirmam que houve um desenvolvimento ao longo do tempo "apenas mostram que a origem das espécies pelo processo de modificação é concebível [...] Eles podem mostrar que o processo de modificação que foi efetuado, e que está se efetuando, determinou mudanças em todos os organismos sujeitos a influências modificadoras. Mas apesar da impossibilidade de chegar em fatos suficientes, eles são incapazes de rastrear as várias fases através das quais qualquer espécie passou para chegar na forma presente, ou de identificar as influências que causaram as modificações sucessivas; mesmo assim, eles podem mostrar que em gerações sucessivas de qualquer espécie existente - animal ou vegetal - quando situada sob condições diferentes das quais estavam previamente - imediatamente começam a sofrer certas mudanças adaptativas em vista das novas condições. Eles podem mostrar que em sucessivas gerações essas mudanças continuam, até que, finalmente, as novas condições tornam-se naturais" (SPENCER, The Development Hypothesis, p. 7. Grifo do autor).
} 
Darwin opôs-se ao fixismo amparando-se principalmente no princípio da seleção natural ${ }^{10}$ e, conforme Bernard Balan mostrou, a prerrogativa de pequenas variações nas sucessivas gerações fortalecia a percepção dos seres vivos dentro de uma história filogenética.

Para Balan, a contribuição de Darwin residiu na nova relação do tempo histórico com a organização dos indivíduos. A partir de Darwin, disse ele, "o tempo torna-se doravante a condição natural da produção de organismos, cuja organização é suposta a fornecer um testemunho histórico"11. Desse modo, as características, a estrutura e os modos de funcionamento observados no presente passaram a ser considerados dentro de uma história filogenética que, na inter-relação com o meio, caracterizaria as formas atuais e permitiria assim pressupor as formas ancestrais.

A história da transformação dos seres, intuída a partir do presente, se deu então, segundo Balan, fora da perspectiva idealista das formas animais. Para o autor, Darwin propôs um sistema que "se engajou desde muito tempo na construção de um edifício científico que conduziu à percepção do reino animal como produto de um devir"12.

Assim, a diversidade da vida estaria em relação com a capacidade de variação que os organismos manifestam em sua descendência. Sabemos que o princípio da seleção natural proposto por Darwin é solidário de uma incessante produção de diferenças na prole das espécies animais. Ao longo do tempo, as variações aleatórias, conjugadas com a relação que estabelecem com o meio, definem a permanência e diferenciação daqueles indivíduos. Como escreveu Darwin,

Em duas regiões muito diferentes em relação às condições de vida, os indivíduos da mesma espécie que apresentem uma constituição ou conformação ligeiramente diferente poderão muitas vezes adaptar-se melhor a este ou aquele local; assim, por um processo de seleção natural [...] pode ser que se formem duas raças ${ }^{13}$.

\footnotetext{
${ }^{10} \mathrm{O}$ princípio da seleção natural sustenta que a continuidade, variação ou extinção de uma espécie ao longo do tempo dependem da confrontação entre variações aleatórias das sucessivas gerações animais com o ambiente que entorna o indivíduo. A perspectiva proposta por Darwin permitiu compreender que as características individuais conjugadas com o meio garantiriam a permanência ou a sucessão da forma viva.

${ }^{11}$ BALAN, L'ordre et le temps, p. 491.

${ }^{12}$ BALAN, L'ordre et le temps, p. 12.

${ }^{13}$ DARWIN, A origem das espécies, p. 62. Notemos que ao enunciar a seleção natural, Darwin reiterou a derivação de um ancestral comum e a relação que as formas vivas que encontramos no presente têm com um processo de modificações ao longo do tempo: "A seleção natural atua quando uma forma possui alguma vantagem sobre as demais na luta pela sobrevivência, sua ação ocorrerá predominantemente em relação às formas que possuem alguma vantagem particular, e a amplitude de um grupo mostra que suas espécies teriam herdado alguma vantagem especial de um possível ancestral comum dotado daquela mesma vantagem" (DARWIN, A origem das espécies, p. 153).
} 
Todavia, o uso mais marcante que Freud fez do evolucionismo não foi o da seleção natural, tampouco da prerrogativa a ela inerente, a variação. Algo que surpreendeu até mesmo Ernest Jones:

Eu procurei em seus escritos, em sua correspondência e em minhas notas relativas às nossas conversas, alusões ao darwinismo, mas sem grande sucesso, se bem que elas poderiam tranquilamente encontrar lugar nos escritos relativos ao desenvolvimento mais remoto do homem; eu me refiro naturalmente à doutrina da evolução através da seleção natural. Um estrangeiro poderia quase crer que Freud não conhecia essa doutrina, o que está certamente fora de questão ${ }^{14}$.

O fato é que o olhar de Freud para as pesquisas evolucionistas centrou-se nas perspectivas históricas que não levaram em conta a importância da variação. Isso notamos na forma como compreendeu que para além da existência ontogenética, acontecimentos ocorridos em um tempo anterior condicionariam a existência no presente por meio de sua sobrevivência. Isto, a despeito de que os efeitos da história filogenética foram reconhecidos por Darwin principalmente nos órgãos rudimentares ou sem utilidade ${ }^{15}$, nas semelhanças e diferenças que os animais têm entre si (o que dificultou a distinção entre espécies e variedades ${ }^{16}$ ) e nos comportamentos que compartilham ${ }^{17}$.

De todo modo, o uso de narrativas históricas por Freud se deu em Totem e tabu (1913), Neuroses de transferência: uma síntese (1915) e Moisés e o monoteísmo (1939), por exemplo. Diante disso, Sulloway chamou a atenção sobre como há um movimento nos escritos freudianos que tende a ir da investigação sobre as causas próximas (como no Projeto para uma psicologia científica), para as causas últimas (como nos textos que se encarregam de investigações da história primeva da espécie humana ${ }^{18}$.

Vejamos agora como o fator temporal, emprestado da Biologia evolutiva, se presentificou em dois postulados evolutivos familiares a Freud, a metamorfose regressiva e a teoria da recapitulação.

\footnotetext{
${ }^{14}$ JONES, $A$ vida e a obra de Sigmund Freud, p. 352.

${ }^{15}$ Darwin considerou que "um órgão rudimentar, em indivíduos adultos, permanece no estado embrionário" (DARWIN, A origem das espécies, p. 512). Adiante considerou que "Os órgãos rudimentares podem ser comparados com as letras mortas conservadas na grafia de algumas palavras e que não são pronunciadas na fala, servindo apenas como uma chave para o descobrimento de sua origem" (DARWIN, A origem das espécies, p. 514). Algo que parece bastante presente no caráter investigativo da psicanálise.

${ }^{16}$ Darwin dedicou o capítulo II da Origem das espécies para abordar essa questão, onde concluiu, dentre outros elementos, que "é vaga e arbitrária a distinção entre espécies e variedade" (DARWIN, $A$ origem das espécies, p. 76).

${ }^{17}$ Aspecto mais explorado no capítulo VIII, Instinto. (DARWIN, A origem das espécies, pp. 283-318).

${ }^{18}$ Para o autor, ao longo da obra de Freud "Houve o movimento de uma teoria próximo-causal para uma teoria último-causal dentro de uma ambição permanente de Freud em vida, de atingir uma solução sintética e psicobiológica para os problemas da mente" (SULLOWAY, Freud: biologist of the mind, p. 365).
} 


\section{Metamorfose regressiva e Teoria da Recapitulação (Lei Biogenética Fundamental)}

Apresentaremos brevemente a ideia de regressão, notadamente em Darwin e Carl Claus antes de passarmos mais detidamente para a teoria da recapitulação.

$\mathrm{O}$ argumento da tendência a um retorno ao arcaico figura nos trabalhos de Claus, professor de Freud durante sua graduação em medicina. Foi sob sua supervisão que Freud teve seu primeiro artigo científico publicado. Em seu Manual de zoologia, Claus apontou que evidências da embriologia indicavam um fenômeno conhecido como metamorfose regressiva. Nesse fenômeno, a tendência de retorno a estágios anteriores em alguns casos pode ser benéfica para o organismo vivo. Como disse:

O curso do desenvolvimento pode, em casos particulares, levar a numerosos retrocessos, então, por conta disso, nós podemos encontrar o animal adulto em uma organização inferior tal qual a da larva. Esse fenômeno, o qual é conhecido como metamorfose regressiva [...] corresponde às demandas da teoria da seleção, segundo a qual sob as mais simples condições de vida, onde a alimentação pode ser mais simplesmente obtida (parasitismo), a degradação e até mesmo a perda de partes, pode ser uma vantagem ao organismo ${ }^{19}$.

Antes dele, também Darwin citou tal mecanismo em um texto publicado em 1868, intitulado Variação de animais e plantas sob domesticação. Notadamente no capítulo XIII, referindo-se ao que chamou de princípio de reversão ou atavismo, indicou a capacidade de um indivíduo reverter características de ancestrais distantes. Segundo Darwin, a reversão se apresenta "quando a criança parece algum ancestral remoto ou algum membro distante em linha colateral - e em um último caso, nós devemos atribuir isso à descendência de todos os membros a um único progenitor"20. Em A descendência do homem, explorou com mais precisão tais aspectos relativos à espécie humana, notadamente no capítulo IV. Neste, Darwin estabeleceu algumas possibilidades relativas às causas da variação nos animais. Destaquemos o que chamou detenções do desenvolvimento, referindo-se a casos de idiotismo cujos indivíduos, como disse, "parecem os tipos inferiores de humanidade" 21. Estes não chegam a falar, focar atenção em algo, mas podem realizar imitações. Sobem escadas de quatro, gostam de subir em árvores e em móveis e são assim comparáveis com o comportamento de animais e de crianças $^{22}$. Já no fenômeno da reversão, ressaltou o aparecimento de formas pertencentes a estágios evolutivos anteriores. Para ele, os

\footnotetext{
${ }^{19}$ CLAUS, Elementary Text-Book of Zoology, p. 158.

${ }^{20}$ DARWIN, The variation of animals and plants under domestication, p. 1.

${ }^{21}$ DARWIN, The descent of Man and selection in relation to sex, p. 121.

${ }^{22}$ DARWIN, The descent of Man and selection in relation to sex, p. 121-2.
} 
fenômenos da reversão "revelam a descendência do homem das formas inferiores de uma maneira inconfundível"23.

Podemos inferir que, em alguma medida, Freud subscreveu esses pressupostos evolutivos em suas elaborações teóricas. Especificamente com relação à regressão, Ritvo comenta que a consideração desse fenômeno pelos biólogos evolucionistas refletia um entendimento alternativo ao criacionismo, o qual considerava que manifestações tais como as citadas acima por Darwin e Claus, tratavam-se de degenerações. Freud, ao entender a histeria enquanto distinta de um estado degradado da natureza humana, disse Ritvo, "se contrapôs e substituiu em sua psicologia do desenvolvimento [a degeneração] pelo conceito de regressão a acontecimentos ou estágios anteriores do desenvolvimento" 24 .

Nos parece que um fenômeno regressivo conforme a perspectiva dos naturalistas frequentados por Freud não destoa do que apresentou em 1920, como veremos adiante, notadamente quando evocou movimentos migratórios de peixes ambicionando comportamentos e locais frequentados por seus ancestrais ${ }^{25}$.

No entanto, parece que a ideia de uma metamorfose regressiva ganhou sustentação com a teoria da recapitulação, a qual prevê que, de forma natural e orgânica, os indivíduos podem retomar estágios evolutivos anteriores ao longo do desenvolvimento ontogenético. Ao incorporá-la à sua psicopatologia juntamente com a regressão em potencial, Freud apresentou uma elaboração bastante singular, como veremos adiante. Por ora, vejamos mais detidamente em que consistia a teoria da recapitulação.

Dentre as teses da Biologia evolutiva que Freud recorreu para fundamentar seus argumentos, a da recapitulação, também conhecida como lei biogenética fundamental, atribuída a Haeckel, teve forte presença no desenvolvimento da teoria freudiana. Sulloway mostra como já era utilizada nas correspondências com Fliess, ao final da década de 1890, para compreender o fenômeno da repressão ${ }^{26}$.

A teoria da recapitulação de Haeckel foi decisiva nas elaborações freudianas em diferentes publicações, como a tendência de elementos psíquicos arcaicos emergirem no tempo presente via neuroses, psicoses, ou mesmo fenômenos oníricos. A lei biogenética fundamental (ou teoria da recapitulação) tem como máxima que "a ontogenia é uma recapitulação abreviada da filogenia". Trata-se de uma ideia que ganhou notoriedade a partir do século XVIII, diz Gould ${ }^{27}$, também devido ao desenvolvimento de ferramentas tecnológicas de observação do desenvolvimento embrionário dos indivíduos, despertando

\footnotetext{
${ }^{23}$ DARWIN, The descent of Man and selection in relation to sex, p. 130.

${ }^{24}$ RITVO, A influência de Darwin sobre Freud, p. 204. Sobre isso, Freud lembrou que "Os casos de atividade sexual observados em crianças eram considerados como signos de degeneração ou corrupção prematura ou como curiosos caprichos da Natureza" (FREUD, Autobiografía, p. 2776).

${ }^{25}$ FREUD, Más allá del Principio del Placer, p. 2525.

${ }^{26}$ SULLOWAY, Freud: biologist of the mind, p. 199-200.

${ }^{27}$ GOULD, Ontogeny and phylogeny, p. 7.
} 
um interesse na semelhança de formas embrionárias entre indivíduos de espécies diferentes, com apontou $\mathrm{Jacob}^{28}$. Algo que, como informa Canguilhem, possibilitou a visualização das "condições lógicas de elaboração de conceitos darwinianos e pósdarwinianos de descendência, ou seja, de transformismo e de evolução, ou seja, de neoformação sucessiva na ordem da ontogênese e da filogênese"29. Tais estudos, continuou, insistiam "sobre a existência de um tipo de correspondência bem observável entre a série animal e o desenvolvimento embrionário"30.

Canguilhem reforçou, na sequência, como a embriologia favoreceu o entendimento de que os animais considerados superiores, como os da espécie humana, de algum modo superaram o que seriam formas adultas de outras espécies. Nesse sentido, um ser anormal seria "um ser que não impulsionou seu desenvolvimento até seu termo. Sua evolução embrionária parou no caminho por uma série de obstáculos que a 'força formadora' encontrou"31. Assim, a embriologia permitiu considerar que um ser anormal é um ser normal, só que atrasado no tempo.

Tais concepções refletiram na abordagem de Haeckel e, consequentemente, na de Freud. Quando este ingressou na faculdade de medicina em 1873, as conferências científicas de Haeckel intituladas História natural da criação ou doutrina científica da evolução estavam em sua quarta edição. Nesta, vemos como Haeckel propôs dividir o estudo da história dos seres vivos entre ontogenia e filogenia. Para ele, dever-se-ia atribuir um campo de estudos dedicado à história do indivíduo, a ontogenia, e outro à história da espécie, a filogenia, dado que o termo para as denominar em alemão, entwicklungsgeschichte, era indiferente a esses dois aspectos temporais da história do desenvolvimento dos seres.

Podemos dizer agora que foi com a proposta de separação entre o estudo da história do indivíduo e o estudo da história da espécie, que Haeckel estabeleceu a lei biogenética fundamental, da qual provém a máxima "a ontogenia é uma recapitulação abreviada da filogenia". Para ele, ao partilharem de uma história ancestral comum, os indivíduos deixam à posteridade não somente o que herdam, "mas também as propriedades individuais que adquiriram durante suas vidas"32. Aliada a essa transmissão do adquirido, a história do desenvolvimento do indivíduo passa a ser, como disse:

[...] uma recapitulação curta, rápida, conforme às leis da hereditariedade $\mathrm{e}$ da adaptação, da filogenia, ou seja, da evolução paleontológica de toda a tribo orgânica do phylum, ao qual pertence o indivíduo examinado. Siga o desenvolvimento individual do homem, do macaco, de um mamífero

\footnotetext{
${ }^{28} \mathrm{JACOB}$, La logique du vivant, p. 78.

${ }^{29}$ CANGUILHEM, Du développement à l'évolution au XIXème siècle, p. 6.

${ }^{30}$ CANGUILHEM, Du développement à l'évolution au XIXème siècle, p. 11.

${ }^{31}$ CANGUILHEM, Du développement à l'évolution au XIXème siècle, p. 12.

${ }^{32}$ HAECKEL, Histoire de la création des êtres organisés d'après les lois naturelles, p. 183.
} 
superior qualquer no útero maternal: vocês encontrarão que o germe incluso no ovo. depois embrião, percorrem uma série de formas bastante diversas ${ }^{33}$.

Para ele, tais formas reproduzem, de maneira geral, "a série de formas ofertadas pela série ancestral histórica dos mamíferos superiores"34. Vejamos como os postulados que apresentamos até aqui foram utilizados por Freud.

\section{Freud: regressão e recapitulação}

Para Ritvo ${ }^{35}$, a presença da Biologia nas elaborações de Freud é um dos aspectos mais notáveis de sua obra. Segundo a autora, trata-se justamente da consideração de que os sintomas e suas origens estão vinculados a emergências no presente de estágios passados ou mais primitivos do desenvolvimento. O próprio enunciado da teoria da recapitulação foi evocado por Freud em diferentes momentos. Em 1913, declarou que tal princípio fundamenta um conjunto de aplicações de sua ciência: "Nos últimos anos veio à psicanálise que o princípio de que 'a ontogenia é uma recapitulação da filogenia' poderia ser também aplicável à vida anímica, e desta reflexão, surgiu uma nova aplicação do interesse de nossa disciplina"36. Uma declaração que precedeu a de que "A psicanálise se viu obrigada a deduzir a vida anímica do adulto a partir da criança, dando assim razão à afirmação de que a criança é o pai do homem"37.

No mesmo ano, em Totem e tabu, declarou que "a vida psíquica destes povos [selvagens] adquire para nós um interesse particular quando vemos nela uma fase anterior, bem conservada, de nosso próprio desenvolvimento" ${ }^{38}$. $\mathrm{Na}$ sequência, estendeu tal pressuposto evolucionista ao temor do incesto, o qual denuncia traços do psiquismo infantil no neurótico, especialmente por este "não ter conseguido libertar-se das condições infantis da psicossexualidade, ou seja, por ter voltado a elas (detenção do desenvolvimento ou regressão"39). Ainda outra vez foi enunciada quando afirmou:

A massa se apresenta a nós, pois, como uma ressurreição da horda primitiva. Assim como o homem primitivo sobrevive potencialmente em cada indivíduo, também toda massa humana pode reconstruir a horda

\footnotetext{
${ }^{33}$ HAECKEL, Histoire de la création des êtres organisés d'après les lois naturelles, p. 189.

${ }^{34}$ HAECKEL, Histoire de la création des êtres organisés d'après les lois naturelles, p. 189-90.

${ }^{35}$ RITVO, A influência de Darwin sobre Freud, p. 208.

${ }^{36}$ FREUD, Multiple interes del psicoanalisis, p. 1863.

${ }^{37}$ FREUD, Multiple interes del psicoanalisis, p. 1862.

${ }^{38}$ FREUD, Tótem y Tabú, p. 1747.

${ }^{39}$ FREUD, Tótem y Tabú, p. 1758.
} 
primitiva. Teremos, assim, que deduzir, que a psicologia coletiva é a psicologia humana mais antiga ${ }^{40}$.

Outra dimensão pela qual a noção de tempo histórico da espécie foi empregada se deu justamente com os processos pulsionais, ao reconhecer tal história em fenômenos clínicos que apresentavam regressões, recapitulações, repetições de comportamentos que, patológicos no presente, teriam sido bem adaptados outrora.

Como informam Gould ${ }^{41}$, Ritvo ${ }^{42}$ e Winograd ${ }^{43}$, Freud, ao se apropriar da teoria da recapitulação, acabou conferindo a ela um estatuto particular, ao considerar o processo patológico como expressão de elementos arcaicos da história da espécie. Segundo estes, a recapitulação aparece vinculada a uma tendência, qual seja, a da regressão. Embora tenhamos, em tese, ultrapassado modos de funcionamento outrora importantes para a espécie, estes nunca teriam deixado de emergir ao longo dos anos como manifestações sintomáticas. Diferentemente de uma sucessão temporal de organizações evolutivas, o que se vê é a coexistência de diferentes tempos evolutivos nas manifestações humanas, um tipo de "formação de compromisso" entre o presente e o passado filogenético.

Segundo Gould, a teoria da recapitulação foi utilizada em outras áreas do conhecimento $^{44}$, uma vez que "a utilizaram para fazer afirmações biológicas sobre a natureza humana e para defender a noção de inevitabilidade de certos aspectos do comportamento e do status social"45. Ela alcançou seu auge justamente do momento em que Freud estudava medicina até seus primeiros anos de carreira, lembra Gould ${ }^{46}$.

Mas o que é preciso destacar é que na psicanálise a atenção foi dada, não às formas físicas dos organismos, mas às formações psíquicas. Conforme Winograd, "tempo e forma estariam, para um Freud profundamente marcado pelo evolucionismo, estreitamente associados, tanto na história da espécie humana quanto nos processos de individuação (anímica, evidentemente)" 47 .

A diferença fundamental na apropriação de Freud é que, segundo Gould, os diferentes estágios evolutivos podem coexistir, o que se justifica em fenômenos regressivos, uma vez que os estágios evolutivos:

\footnotetext{
${ }^{40}$ FREUD, Psicología de las masas y análisis del yo, p. 2596.

${ }^{41}$ GOULD, Ontogeny and phylogeny.

${ }^{42}$ RITVO, $A$ influência de Darwin sobre Freud.

${ }^{43}$ WINOGRAD, Freud e a fábrica da alma.

44 Como na criminologia (através dos trabalhos de Cesare Lombroso na justificativa para políticas e concepções racistas), na psicologia da criança (através de James Baldwin e Jean Piaget), na educação (notadamente com John Dewey) em enfim, na psicanálise (GOULD, Ontogeny and phylogeny, pp.115-166).

${ }^{45}$ GOULD, Ontogeny and phylogeny, p. 165.

${ }^{46}$ GOULD, Ontogeny and phylogeny, p. 156.

${ }^{47}$ WINOGRAD, Freud e a fábrica da alma, p. 169.
} 
[...] aparecem durante a ontogenia em uma ordem filogenética própria, mas um estágio antigo não desaparece para abrir caminho para um posterior. Os estágios mais antigos são caracteristicamente reprimidos no adulto saudável, mas eles não precisam desaparecer ${ }^{48}$.

A metáfora arqueológica de Roma, que figura em $\mathrm{O}$ mal-estar na civilização, ilustra tal coexistência. Ali Freud admitiu que as sucessivas construções realizadas em Roma não podem ocupar os mesmos espaços, que não podemos visualizar na cidade atual todas suas construções até o presente. No entanto, a analogia é, segundo Freud, insuficiente, uma vez que os tempos se alocam diferentemente no psiquismo. Neste, disse Freud, "tudo se conserva de alguma maneira e pode voltar a surgir em circunstâncias favoráveis, como, por exemplo, mediante uma regressão de suficiente profundidade" 49 .

Para ele, na vida psíquica o pretérito está sempre conservado e pode, contemporaneamente ao ontogenético, se manifestar. Diferentemente dos seres vivos, em cujo desenvolvimento o material fisiológico é transformado, no psiquismo, "é possível essa persistência de todos os estágios prévios junto à forma definitiva, e que não podemos representar graficamente tal fenômeno"50, admitiu Freud. Ademais, continuou, "na vida psíquica a conservação do pretérito é a regra, mais do que uma curiosa exceção" 51 .

Lembremos que em $O$ múltiplo interesse da psicanálise, Freud mostrou como o passado pode ser concomitante no presente dos indivíduos, uma vez que o pretérito anímico não desaparece com as novas aquisições. Na verdade, para ele:

Subsistem ao lado daquilo que dele surgiu em uma simultaneidade [...] A prova dessa afirmação é que os sonhos do homem normal reavivam todas as noites seu caráter infantil e revertem toda sua vida anímica a um grau infantil. Essa mesma regressão ao infantilismo psíquico tem efeito também nas neuroses e psicoses, cujas singularidades hão de ser descritas em sua grande maioria, como arcaísmos psíquicos ${ }^{52}$.

Neste sentido, Gould conclui que na relação com os processos patológicos, e também com os normais, a teoria da recapitulação teria permitido a Freud situar as neuroses como:

[...] expressões de uma energia sexual apropriada às crianças, mas normalmente reprimida e suplantada nos adultos. Elas emergem somente porque estágios mentais primevos sobrevivem nos adultos (pensamento normal em um estado reprimido). [...] Neuroses não são apenas uma

\footnotetext{
${ }^{48}$ GOULD, Ontogeny and phylogeny, p. 157.

${ }^{49}$ FREUD, El malestar en la cultura, p. 3020.

${ }^{50}$ FREUD, El malestar en la cultura, p. 3022.

${ }^{51}$ FREUD, El malestar en la cultura, p. 3022.

${ }^{52}$ FREUD, Multiple interes del psicoanalisis, p. 1863.
} 
retenção anormal de estágios apropriados às crianças; elas também representam a expressão de tendências ancestrais - um atavismo a se evitar em qualquer leitura progressista da evolução ${ }^{53}$.

Podemos considerar que na investigação sobre o desencadeamento dos sintomas, a relação destes com o passado do paciente embasou elementos de sua concepção do patológico. Passemos à próxima seção com vistas a explorar os efeitos evolucionários na concepção de pulsão proposta em Além do princípio do prazer.

\section{O Além do passado}

$\mathrm{Na}$ sequência do que foi até aqui apresentado, indicaremos a presença dos referenciais evolucionários em sua noção de pulsão de morte. Em Além do princípio do prazer, conforme o próprio título indica, a tese que Freud procurou sustentar foi a da existência de um princípio organizador do psiquismo ainda mais anterior que o princípio do prazer. Ele considerou essa possibilidade a partir da observação de certos fenômenos recorrentes, como os sonhos presentes em neuroses traumáticas, as características do brincar infantil, além da tendência à repetição de relatos por pacientes neuróticos durante a análise.

Todos pensados no entorno do fenômeno da regressão, como apresentado em Além do princípio do prazer. Observemos que, logo na primeira sessão da obra, Freud considerou duas circunstâncias que fazem fracassar o propósito do princípio do prazer, as quais estariam em acordo com os modelos desenvolvimentistas do evolucionismo. $\mathrm{O}$ primeiro indicador do fracasso do princípio do prazer seria o próprio perseverar na existência, uma vez que seu funcionamento "é inútil e até perigoso em alto grau, para a autoafirmação do organismo diante das dificuldades do mundo exterior" ${ }^{54}$, definiu Freud. Já o princípio de realidade intervém com vistas a postergar a satisfação imediata, para obtê-la posteriormente. Desse modo, mesmo com a intervenção deste último, diz Freud, "O princípio do prazer continua ainda, por um longo tempo, regendo o funcionamento do instinto sexual, mais dificilmente 'educável'"55. Neste caso, uma segunda fonte de

\footnotetext{
${ }^{53}$ GOULD, Ontogeny and phylogeny, p. 158. Neste caso, o que também está em jogo é a aplicação da teoria da evolução e da recapitulação de uma forma distinta, vale dizer, que não pressupõe a linearidade do tempo cronológico, que não pressupõe uma sucessão linear do simples ao complexo, do menos desenvolvido ao mais desenvolvido. Segundo Winograd, "no anímico, o tempo opera de modo não-linear, é espiralado e pontual. Neste tempo, a evolução não se daria em direção à perfeição, mas, sim, no sentido de um desdobramento conforme o contexto e a história. Desdobramento no qual os momentos anteriores não se apagam completamente, pois deixam marcas que, eventualmente, podem permitir a sua (re)construção e que, sobretudo, determinam as formas que surgem no presente" (WINOGRAD, Freud e a filogenia anímica, p. 75).

${ }^{54}$ FREUD, Más allá del Principio del Placer, p. 2509.

${ }^{55}$ FREUD, Más allá del Principio del Placer, p. 2509.
} 
desprazer relativa à interrupção do princípio do prazer decorre de um conflito entre tempos evolutivos. Nesse caso, o desprazer:

Surge de conflitos e dissociações que têm lugar no aparato psíquico, enquanto o eu tem sua evolução até organizações de complexidade superior. Quase toda a energia que preenche o aparato procede dos impulsos instintivos que a ele são inerentes, mas nem todos eles são admitidos às mesmas fases evolutivas ${ }^{56}$.

Foi depois de inserir esses dois tipos de perturbações ao princípio do prazer que Freud observou a existência de outra categoria dessa ordem, relativa à percepção de elementos externos, os quais o paciente pode reconhecer como nocivos.

Freud então passou à segunda seção de seu trabalho indicando características oníricas da neurose traumática e o brincar de fazer objetos desaparecerem e aparecerem, realizado por crianças pequenas. No caso dos sonhos decorrentes de neuroses traumáticas, parece haver uma contradição com o fato do sonho ser uma realização de desejos. Ele sugeriu que tais sonhos expressam a existência de "misteriosas tendências masoquistas do eu". Já nos jogos infantis, as crianças parecem reatualizar situações de desagrado, que as fizeram sofrer. Assim, estes casos indicaram a existência de tendências mais primitivas que o princípio do prazer ${ }^{57}$. Na seção III apresentou um exemplo decisivo, o fenômeno clínico de repetição do reprimido enquanto acontecimento atual. Este ocorre quando o paciente repete, na transferência com o médico, conteúdos fragmentários de sua vida sexual infantil, todos relativos ao complexo de Édipo.

Para Freud, a "compulsão à repetição" faria os pacientes reproduzirem conteúdos desprazerosos do passado, como frustrações na infância relativas ao Édipo ${ }^{58}$. Algo como um "perpétuo retorno do mesmo", uma compulsão situada para além do princípio do prazer, que "parece ser mais primitiva, elementar e instintiva que o princípio"59.

No caso de uma situação de análise, Freud notou a tendência do paciente "de repetir, na transferência, os acontecimentos da infância [...] o enfermo se conduz nesses casos de modo completamente infantil"60. A explicação de tal tendência estaria, como disse, na natureza dos instintos:

Um instinto seria, pois, uma tendência própria do orgânico vivo à reconstrução de um estado anterior, que o animado teve que abandonar sob

\footnotetext{
${ }^{56}$ FREUD, Más allá del Principio del Placer, p. 2509.

${ }^{57}$ FREUD, Más allá del Principio del Placer, p. 2513.

${ }^{58}$ FREUD, Más allá del Principio del Placer, p. 2515.

${ }^{59}$ FREUD, Más allá del Principio del Placer, p. 2517.

${ }^{60}$ FREUD, Más allá del Principio del Placer, p. 2524.
} 
o influxo de forças exteriores, perturbadoras; uma espécie de elasticidade orgânica ou, a manifestação da inércia da vida orgânica ${ }^{61}$.

A Biologia mostra o condicionamento histórico dos instintos dos animais. Freud citou como exemplo as migrações de peixes cuja programação instintiva consistia em buscar "os lugares que sua espécie residira primitivamente"62. Ademais, considerou que nos "feitos da Embriologia temos as mais magníficas provas da obsessão orgânica de repetição"63. A embriologia mostra que "o gérmen de um animal vivo se encontra forçado a repetir em sua evolução - ainda que muito abreviadamente - todas as formas das quais o animal descende, ao invés de marchar rapidamente pelo caminho mais curto de sua definitiva estrutura"64, concluiu Freud.

Apesar de ter reconhecido a possibilidade de um instinto estar voltado também à adição de novas formas, se disse interessado em levar às últimas consequências "a hipótese de que todos os instintos querem reconstruir algo anterior"65.

Desse modo, se os instintos têm uma tendência a regredir ou a reconstruir o passado, questionou, "devemos atribuir todos os êxitos da evolução orgânica a influências exteriores, perturbadoras e desviantes"66. Neste caso, o mais elementar ser orgânico não almejaria transformar-se, antes tenderia a repetir um mesmo percurso vital. Recebendo forças transformadoras no curso vital, procurariam também conservá-las para a repetição. Assim, o organismo parece buscar alcançar um estado antigo, buscar o ponto de partida outrora abandonado.

Ao longo da história evolutiva, influências exteriores teriam desviado a substância viva de sua tendência de retorno ao inanimado. Mas os instintos sexuais, que são os verdadeiros instintos de vida, diz Freud, "conservam a vida do organismo por mais tempo" e, como adicionou em 1923 em nota de rodapé, "é a eles apenas que podemos atribuir um impulso interno em direção ao 'progresso' e em direção a um desenvolvimento mais elevado"67. Assim, enquanto o instinto mais primitivo visa alcançar o inorgânico o quanto antes, o outro "retrocede ao chegar a determinado lugar de dito caminho, para voltar a empreender novamente desde um ponto anterior e prolongar assim sua duração"68.

Há nesta afirmação o apoio na tese acerca da regressão no caminho evolutivo apoiada na teoria da recapitulação. Além disso, não foi demonstrado ainda a existência de um instinto de evolução do mundo animal. Isto porque, ponderou, "é talvez tão só um juízo

\footnotetext{
${ }^{61}$ FREUD, Más allá del Principio del Placer, p. 2525.

${ }^{62}$ FREUD, Más allá del Principio del Placer, p. 2525.

${ }^{63}$ FREUD, Más allá del Principio del Placer, p. 2525.

${ }^{64}$ FREUD, Más allá del Principio del Placer, p. 2525.

${ }^{65}$ FREUD, Más allá del Principio del Placer, p. 2525.

${ }^{66}$ FREUD, Más allá del Principio del Placer, p. 2526.

${ }^{67}$ FREUD, Más allá del Principio del Placer, p. 2527.

${ }^{68}$ FREUD, Más allá del Principio del Placer, p. 2527.
} 
pessoal a declaração de que um grau evolutivo é superior ao outro, e ademais, a Biologia nos mostra que a superevolução em um ponto se consegue com frequência pela regressão de outro"69.

Para Freud, a evolução da espécie humana, sua complexidade, seria na verdade uma consequência da:

Repressão dos instintos, processo ao qual se deve o mais valioso da civilização humana [...] O caminho para trás, até a total satisfação, é sempre deslocado para as resistências que mantêm a repressão, e desse modo não resta outro remédio que não avançar na direção evolutiva que permanece livre, ainda que sem esperança de dar fim ao processo e poder alcançar a meta $^{70}$.

Assim, o fato da civilização ser resultado da repressão instintual não impede que os instintos mais primordiais coexistam e mobilizem os indivíduos a regredirem a estágios próprios das condições arcaicas de existência da matéria viva. Como definiu ao final da obra, o instinto está atrelado à "necessidade de reconstituir um estado anterior"71.

Afinal, como disse:

Se como experiência, sem exceção alguma, temos que aceitar que todo o vivente morre por fundamentos internos, voltando ao inorgânico, poderíamos dizer: A meta de toda vida é a morte. E com igual fundamento: O inanimado existiu antes do animado"72.

\section{Considerações finais}

Nesta conclusão pretendemos, mobilizados pela chave de leitura apresentada por Georges Canguilhem quanto à Biologia evolutiva, finalizar com uma rápida consideração sobre o papel normativo das elaborações de Freud.

Tal chave de leitura remete à constatação de que o patológico está estritamente vinculado com certa expectativa que se constrói sobre a natureza dos seres. Segundo Canguilhem:

[...] não há, em tese e a priori, diferença ontológica entre uma forma viva perfeita e uma forma viva malograda. Aliás, será lícito falar de formas vivas

\footnotetext{
${ }^{69}$ FREUD, Más allá del Principio del Placer, p. 2528.

${ }^{70}$ FREUD, Más allá del Principio del Placer, p. 2528.

${ }^{71}$ FREUD, Más allá del Principio del Placer, p. 2537.

${ }^{72}$ FREUD, Más allá del Principio del Placer, p. 2526.
} 
malogradas? Que falha pode-se detectar em um ser vivo, enquanto não se tiver fixado a natureza de suas obrigações como ser vivo ${ }^{73}$

Para Canguilhem, a ideia de natureza de um organismo vivo é fortemente amparada pelas elaborações das ciências da vida, tais como a Biologia. Em outra obra, O conhecimento da vida, reforçou esse argumento, despotencializando a noção de funcionamento patológico. Para ele:

[...] se considerarmos o mundo vivo como uma tentativa de hierarquização das formas possíveis, não há em si, e a priori, diferença entre uma forma bem-sucedida e uma forma falhada. Para falar com propriedade, não há nem mesmo formas falhadas. Nada pode faltar a um vivente, se admitirmos de bom grado que há mil e uma maneiras de viver. [...] na ordem da vida, não há sucessos que desvalorizem radicalmente outras tentativas, fazendo-as parecer falhadas ${ }^{74}$.

Isso porque as noções que as ciências da vida propõem quanto às formas vivas, no estabelecimento de regularidades e tendências morfológicas, fisiológicas e comportamentais, são solidárias de um saber biológico dotado de uma autoridade científica para o estabelecimento daquilo que seria a natureza de um organismo vivo. Desse modo, o modelo de natureza assim obtido forneceria certa expectativa sobre o funcionamento dos organismos. Como afirmou em O problema da normalidade na história do pensamento biológico, tal expectativa foi consolidada ao longo do século XIX a partir de observações realizadas por naturalistas. Os estudos da nascente Biologia permitiram entender que "A forma de um organismo se exprime numa constância aproximada, que é o que se verifica na maior parte dos casos. É o que nos autoriza a considerar a forma como uma norma, em relação à qual a exceção é qualificada como anormalidade"75.

Isso corresponderia no campo da fisiologia, como escreveu em $\mathrm{O}$ normal e o patológico, que:

A atribuição de um valor "normal" às constantes cujo conteúdo é determinado cientificamente pela fisiologia reflete a relação da ciência da vida [biologia] com a atividade normativa da vida e, no que se refere à ciência humana, com as técnicas biológicas de produção e de instauração do normal, mais especificamente com a medicina ${ }^{76}$.

O fato da Biologia e seus campos adjacentes cumprirem função normativa na qualificação das manifestações humanas, oferecendo referenciais qualificativos quanto ao

\footnotetext{
${ }^{73}$ CANGUILHEM, O normal e o patológico, p. 5.

${ }^{74}$ CANGUILHEM, $O$ conhecimento da vida, p. 175.

${ }^{75}$ CANGUILHEM, O problema da normalidade na história do pensamento biológico, p. 110.

${ }^{76}$ CANGUILHEM, O normal e o patológico, p. 166.
} 
que seria próprio ou não a um indivíduo, pareceu ser significativamente presente nos escritos freudianos que analisamos. Nos parece que a apropriação de princípios evolucionistas permitiu a Freud a construção dos tais critérios distintivos do normal e do patológico na psicanálise.

Inspirados por Canguilhem, vemos que o recurso à Biologia evolutiva serviu de baliza para Freud estabelecer sua concepção psicanalítica de indivíduo dotado de um psiquismo cuja expressão patológica é uma tendência de sua natureza, especialmente quanto ao caráter regressivo das pulsões.

Isso nos permite melhor compreender como a adesão de Freud ao evolucionismo não foi propriamente uma adesão a Darwin, mas sim a Haeckel. Assim vinculou novas formas de existência a regressões a tempos evolutivos remotos, vinculando com significativa frequência o patológico ao pretérito, à formação de compromisso entre o presente e o passado. Enfim, repetição e patologia em lugar de variação e de diferença no curso da história animal da espécie humana.

Para encerrar, perguntamos como seria a psicanálise freudiana se seu fundador tivesse visto no patológico menos elementos vinculantes com o passado (Haeckel), e mais a incessante emergência de elementos novos na história da espécie humana, de variações cuja relação com o meio definiria sua continuidade ou não (Darwin)? Certamente o adjetivo "patológico" perderia seu valor para a psicanálise e os comportamentos humanos desviantes seriam vistos como a irrupção de uma nova forma e de determinado relacionamento com a cultura. A variação, não mais a patologia, seria algo propositivo em relação ao presente e ao futuro, e não um "resto arqueológico" ou mesmo uma regressão ao passado primevo da espécie humana. Enfim, a manifestação patológica ganharia novas leituras que acabariam por tornar a própria ideia de patologia algo patológica.

\section{Referências}

ASSOUN, Paul-Laurent. Introduction à l'épistémologie freudienne. Paris: Payot, 1981.

ASSOUN, Paul-Laurent. Freudisme et darwinisme. In P. Tort (Org.) Dictionnaire $d u$ Darwinisme et de l'evolution. Paris: PUF, 1996.

BALAN, Bernard. L'ordre et le temps. Paris: J. Vrin, 1979

BERNFELD, Siegfried. Freud's scientific beginnings. American Imago. Vol. 6, N. 3, pp. 163-96, setembro, 1949.

BOEHLICH, Walter; FREUD, Ernst. Lettres de jeunesse. Paris: Gallimard, 1990. 
CANGUILHEM, Georges. L'Homme et l'animal du point de vue psychologique selon Charles Darwin. In : Études d'histoire et de philosophie des sciences. 3. Ed. Paris: Librairie Pshilosophique J. Vrin, 1975.

CANGUILHEM, Georges. O problema da normalidade na história do pensamento biológico. In: CANGUILHEM, Georges. Ideologia e racionalidade nas ciências da vida. Lisboa: Edições 70, 1977.

CANGUILHEM, Georges. Du développement à l'évolution au XIXème siècle. 2. ed. Presses Universitaires de France, 1985.

CANGUILHEM, Georges. O conhecimento da vida. Rio de Janeiro: Forense Universitária, 2012.

CANGUILHEM, Georges. O normal e o patológico. 6. ed. Revisada. Rio de Janeiro: Forense Universitária, 2014.

CLAUS, Carl. Elementary Text-Book of Zoology. 2. ed. New York: Macmillan \& Co. London: Swan Sonnenschein \& Co., 1884

DARWIN, Charles. The descent of Man and selection in relation to sex. London: John Murray, 1871.

DARWIN, Charles. The variation of animals and plants under domestication. 2. ed. London: John Murray, 1875.

DARWIN, Charles. A origem das espécies. 2. Ed. São Paulo: Martin Claret, 2010.

FREUD, Sigmund. (1877) Observations de la conformation de l'organe lobé de l'anguille décrit comme grande gérminale mâle, de 1877. In: FÉDIDA, Pierre; WIDLÖCHER, Daniel (orgs.) Les évolutions: phylogenèse de l'individuation. Paris: PUF, 1994.

FREUD, Sigmund. (1897). Sinopses dos escritos do Dr. Sigmund Freud 1877/1897. In: Edição Standard Brasileira das Obras Psicológicas Completas de Sigmund Freud. Vol. 3. Rio de Janeiro: Imago, 1976.

FREUD, Sigmund. (1913) Multiple interes del psicoanalisis. In: Obras Completas. 4. Ed. Madrid: Biblioteca Nueva, 1981.

FREUD, Sigmund. (1913b) Tótem y Tabú. In: Obras Completas. 4. Ed. Madrid: Biblioteca Nueva, 1981.

FREUD, Sigmund. (1916-7) Psicoanálisis. In: Obras Completas. 4. Ed. Madrid: Biblioteca Nueva, 1981.

FREUD, Sigmund. (1917) Una dificultad del psicoanálisis. In: Obras Completas. 4. Ed. Madrid: Biblioteca Nueva, 1981. 
FREUD, Sigmund. (1920) Más allá del Principio del Placer In: Obras Completas. 4. Ed. Madrid: Biblioteca Nueva, 1981.

FREUD, Sigmund. (1921) Psicología de las masas y análisis del yo. In: Obras Completas. 4. Ed. Madrid: Biblioteca Nueva, 1981.

FREUD, Sigmund. (1925) Autobiografía. In: Obras Completas. 4. Ed. Madrid: Biblioteca Nueva, 1981.

FREUD, Sigmund. (1926) Análisis profano (psicoanálisis y medicina): conversaciones con una persona imparcial. In: Obras Completas. 4. Ed. Madrid: Biblioteca Nueva, 1981.

FREUD, Sigmund. (1930) El malestar en la cultura. In: Obras Completas. 4. Ed. Madrid: Biblioteca Nueva, 1981.

FREUD, Sigmund. (1933). Nuevas lecciones introductorias al psicoanalisis. In: Obras Completas. 4. Ed. Madrid: Biblioteca Nueva, 1981.

GOULD, Stephen Jay. Ontogeny and phylogeny. Cambridge (Mass., Estados Unidos): Belknap Press of Harvard University Press, 1977

HAECKEL, Ernst. Histoire de la création des êtres organisés d'après les lois naturelles: conférences scientifiques sur la doctrine de l'évolution en général et celle de Darwin, Goethe et Lamarck en particulier. 2. ed. Paris: C. Reinwald et Cie. Libraires-Éditeurs, 1877. JACOB, François. La logique du vivant : une histoire de l'heredité. Paris : Gallimard, 1970. JONES, Ernest. A vida e a obra de Sigmund Freud: última fase (1919-1939). Rio de Janeiro: Imago, 1988.

KELLY, Alfred. The descent of Darwin: The popularisation of Darwinism in Germany, 1860-1914. The University of North Carolina Press, 1981.

RITVO, Lucille. B. A influência de Darwin sobre Freud: um conto de duas ciências. Rio de Janeiro: Imago Ed., 1992.

SIMANKE, Richard Theisen. A psicanálise freudiana e a dualidade entre ciências naturais e ciências humanas. Scientiae Studia. V. 7, n. 2, p. 221-35, 2009.

SPENCER, Herbert. The Development Hypothesis. Essays Scientific, Political \& Speculative. Williams and Norgate (3 vols) pp.1-7], 1852.

SULLOWAY, Frank. Freud: biologist of the mind. 2. ed. Harvard University Press, 1992.

WINOGRAD, Monah. Freud e a filogenia anímica. Revista do Departamento de Psicologia - UFF. V. 19, n. 1, p. 69-82, jan-jun, 2007.

WINOGRAD, Monah. Freud e a fábrica da alma: sobre a relação corpo-psiquismo em Psicanálise. Curitiba: Appris, 2013. 